\title{
Evaluation of the Nutrition Education at Primary School (NEAPS) programme
}

\author{
Sharon Friel ${ }^{*}$, Cecily Kelleher, Paula Campbell and Geraldine Nolan \\ National Nutrition Surveillance Centre, Department of Health Promotion, Clinical Sciences Institute, \\ National University of Ireland, Galway, Republic of Ireland
}

Submitted 10 March 1998: Accepted 29 March 1999

\begin{abstract}
Objective: To assess the impact and suitability of a pilot dietary educational programme for primary school pupils. The Nutrition Education at Primary School (NEAPS) programme aimed to build awareness of the benefits of healthy eating, induce positive behaviour change and increase the children's knowledge.

Design: A comparative quasi-experimental study with follow-up after 3 months.

Setting: Eight primary schools in the Eastern and North Western Health Boards and three control schools in the same board regions.

Subjects: Data were used from 821 Irish school children aged 8-10 years old.

Methods: The education programme comprised 20 sessions over 10 weeks including circular worksheets, homework assignments and an aerobic exercise regime. At baseline and after 3 months pupils completed food diaries and a validated food pairing questionnaire on food behaviour, knowledge and preferences.

Results: Significant differences were found in the intervention children's behaviour and preference levels after the NEAPS programme $(P<0.01$ in both sections). Knowledge levels were very high at baseline and though some individual items improved, average change overall was not significant. Rural children appeared to benefit more in behaviour and preferences from the programme $(P<0.01)$. The NEAPS programme appeared to be less effective in pupils in disadvantaged areas $(P<$ 0.01 for each of the sections: behaviour, preference and knowledge). One hundred and eighty-seven children completed food diaries. The intervention children's consumption of fruit and vegetables increased, and they consumed less salty snacks after the programme. Rural children were confirmed to have healthier diets at baseline.

Conclusions: Following the NEAPS pilot programme positive changes were seen in the school children's eating behaviour and preferences for healthier foodstuffs. This suggests successful development of a culturally sensitive nutrition education programme for school children aged 8-10 years.
\end{abstract}

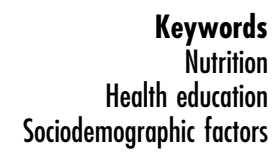

Keywords

Nutrition Sociodemographic factors
Nutrition health education has become increasingly prominent in schools' programmes worldwide, either as part of dedicated courses such as home economics or wider skills-based programmes ${ }^{1-11}$. There is evidence that young people develop risk factors ${ }^{12-14}$ and disease evidence for coronary heart disease early ${ }^{15,16}$ and, in Ireland as elsewhere ${ }^{17}$, obesity is becoming a major public health problem for children. Patterns of eating are changing with a strong reliance on frequent snacking and consumption of so-called junk foods ${ }^{3,18-23}$.

A variety of programmes have improved knowledge $^{2,24}$ and in some cases reported behaviour ${ }^{1,8,11}$. Evaluation of effectiveness can be problematic as improved knowledge may not necessarily affect longterm behaviour ${ }^{25}$. However, structured programmes can contribute to a wider context-based approach ${ }^{11}$. Bandura's social learning theory ${ }^{26}$ has formed the basis of several programmes ${ }^{3,7}$ in that it encourages capabilities and self-control and employs re-enforcement techniques. The Hearty Heart programme was developed as part of the Minnesota Heart Study and has been evaluated $^{8}$. A 2-year pilot nutrition health education programme in primary schools (NEAPS) was set up based on this model under the auspices of the Departments of Education and Health in conjunction with the North Western and Eastern Health Boards. Until this study was undertaken there had been no Irish nutrition intervention programmes targeted at primary school children as part of the teaching curriculum, though it was a component in various schools' health education programmes. The intention was to design suitable educational materials for Irish school children aged 8-10 years old in order to build awareness of the benefits of healthy eating and regular exercise, to 
induce positive behaviour changes towards healthy foods and to increase children's knowledge about healthy eating.

We undertook this evaluation of the pilot programme to assess changes in the children's knowledge, behaviour and preferences of healthy foodstuffs and to determine if such changes were dependent on location or school classification. The subjective success of the programme as felt by the children, teachers and parents was also determined but are not included in this evaluation report.

\section{Subjects and methods}

A total of eight schools were chosen by the Department of Education inspectors for participation in the 10-week pilot intervention programme, primarily with demographic considerations in mind. Four schools were located in the North Western Health Board and three of these were in rural areas, whilst the four schools in the Eastern Health Board were urban and sited mainly in economically disadvantaged areas. The third and fourth classes of each school were chosen to comply with the target age group of $8-10$ years. Three control schools were randomly chosen by the project officer, two in the North Western Health Board (one urban) and one urban school in the Eastern Health Board.

\section{Materials}

Programme materials entitled 'Hearty Heart and Friends' were developed around a group of extraterrestrial cartoon characters based on the American Hearty Heart model. The resource materials consisted of lesson plans, activity worksheets for pupils, a home team pack to involve parents and the food diaries. A 10-week comparative quasi-experimental design was used with intervention schools receiving $20 \times 30$-minute sessions using a cross-curriculum approach. In-service training was provided for participating teachers which identified nutritional principles and methods of teaching children the skills necessary to make healthy decisions. A baseline questionnaire survey was carried out in both intervention and control schools prior to the project commencement and simultaneously all children were asked to complete a food diary relating to their morning breaks and lunches over a 5-day school week. Both measures were repeated post-intervention.

The Minnesota Heart Health programme used a foodpairing questionnaire which comprised three sections: knowledge, preference and behaviour. In each section there were 18 pairs of pictures of foodstuffs, one signifying the healthy choice and the other the unhealthy one. Each section contained the same 18 food pairs and the respondents were asked to circle which food they ate most often, which they liked best and which food they thought was better for them. This type of visual instrument was felt to be appropriate for the age group. As it had been validated on a similar group of children in the United States no changes were made apart from altering the names of some foodstuffs to colloquial English.

\section{Data analysis}

Schools were categorized as urban or rural and according to location in socioeconomically disadvantaged areas. Student's $t$-test, analysis of variance (ANOVA) and chi-square statistical methods were used to analyse for differences across groups as appropriate. Each food in the pair was given a score, $1=$ healthy choice and $2=$ unhealthy choice. In each section, a total score for the 18 food pairs was calculated for each child, with a minimum of 18 and maximum of 36 being possible. At baseline, Student's $t$-test was utilized to assess whether differences existed between the experimental and control children's behaviour, preference and knowledge scores. Changes in average score over time in both intervention and control children were analysed using ANOVA tests. Comparisons were also made using chi-square statistics between the percentages of children choosing the healthier food choice in the different groupings.

The diary information was categorized according to the four food groups: (i) meat, fish or alternatives, (ii) dairy products, (iii) fruit and vegetables, and (iv) cereals including bread and potatoes. If there was missing information about portion size this was arbitrarily designated, e.g. sandwiches at lunch were denoted as two servings (two slices) or potatoes at dinner were denoted as two servings (two small potatoes), milk as equivalent to half a glass, or a bowl of cereal as one portion. While this might affect the precision of the findings to some degree it was felt unlikely to introduce significant bias into the group comparisons. The information was categorized by frequency of consumption and the percentage of individuals in each category reported for the purposes of analysis. Other specific items, such as chips, orange juice, salty or high sugar snacks and drinks were also categorized according to frequency of consumption. Analysis of this section was by means of chi-square testing.

\section{Results}

A total of 821 children participated in the study, 453 in the intervention schools and 368 in the control schools. Seventy-eight per cent of the intervention children (353) and 84\% (308) of the controls responded to the pre-test questionnaire, and post-test 336 intervention children and 274 controls completed it. Sixty-four per cent of these children completed pre- and post-test 
Table 1 Averages of food-pairing questionnaire scores for intervention and control children in urban and rural school locations, mean (standard deviation)

\begin{tabular}{|c|c|c|c|c|c|c|}
\hline & \multicolumn{3}{|c|}{ Intervention } & \multicolumn{3}{|c|}{ Control } \\
\hline & $\begin{array}{l}\text { All } \\
\bar{x}(\sigma)\end{array}$ & $\begin{array}{l}\text { Urban } \\
\overline{\mathrm{x}}(\sigma)\end{array}$ & $\begin{array}{l}\text { Rural } \\
\overline{\mathrm{x}}(\sigma)\end{array}$ & $\begin{array}{c}\text { All } \\
\bar{x}(\sigma)\end{array}$ & $\begin{array}{l}\text { Urban } \\
\overline{\mathrm{x}}(\sigma)\end{array}$ & $\begin{array}{l}\text { Rural } \\
\overline{\mathrm{x}}(\sigma)\end{array}$ \\
\hline \multicolumn{7}{|l|}{ Behaviour } \\
\hline Pre-test & $25.4(3.6)$ & $25.2(3.7)$ & $25.3(3.3)$ & $26.5(3.3)$ & $26.5(3.3)$ & $27.1(3.5)$ \\
\hline $\begin{array}{l}\text { No. respondents } \\
\text { Post-test }\end{array}$ & $\begin{array}{c}353 \\
24.2(3.7)\end{array}$ & $\begin{array}{c}220 \\
24.1(3.8)\end{array}$ & $\begin{array}{c}133 \\
24.4(3.5)\end{array}$ & $\begin{array}{c}307 \\
26.8(3.5)\end{array}$ & $\begin{array}{c}275 \\
26.7(3.5)\end{array}$ & $\begin{array}{c}32 \\
27.7(3.1)\end{array}$ \\
\hline No. respondents & 336 & 197 & 139 & 274 & 243 & 31 \\
\hline Significance & $<0.01$ & & & NS & & \\
\hline \multicolumn{7}{|l|}{ Preference } \\
\hline Pre-test & $27.4(4.2)$ & $26.9(4.4)$ & $28.2(3.8)$ & $29.4(3.8)$ & $29.3(3.7)$ & $29.9(4.2)$ \\
\hline No. respondents & 353 & 220 & 133 & 308 & 276 & \\
\hline Post-test & $26.2(4.0)$ & $26.2(4.1)$ & $26.3(4.0)$ & $30.0(3.6)$ & $30.0(3.6)$ & $29.9(3.5)$ \\
\hline No. respondents & 335 & 195 & 140 & 274 & 243 & 31 \\
\hline Significance & $<0.01$ & & & NS & & \\
\hline \multicolumn{7}{|l|}{ Knowledge } \\
\hline Pre-test & $20.5(2.4)$ & $20.4(2.6)$ & $20.6(2.0)$ & $19.7(1.6)$ & $19.6(1.6)$ & $19.9(1.5)$ \\
\hline No. respondents & 353 & 220 & 133 & 308 & 276 & 32 \\
\hline Post-test & $19.7(2.1)$ & $19.9(2.4)$ & $19.4(1.6)$ & $19.3(1.7)$ & $19.3(1.7)$ & $19.7(1.7)$ \\
\hline No. respondents & 334 & 195 & 139 & 274 & 243 & 31 \\
\hline Significance & NS & & & NS & & \\
\hline
\end{tabular}

NS, not significant.

A low mean score, $\bar{x}$, indicates more healthier foodstuffs chosen.

diaries as well and a random selection of these $(n=187)$ were analysed for the purposes of the evaluation.

\section{Questionnaire findings}

There were significant differences in mean scores which favoured the intervention group in behaviour and preference scores at baseline (Table 1). Baseline knowledge levels were very high for most items in both groups. There were no significant differences between the urban and rural groupings overall although there were differences in behaviour and preference categories in favour of the intervention schools in each locality and in knowledge in favour of urban controls (all $P<0.01$ ). Following the programme the intervention group demonstrated significant changes in reported behaviour and food preferences overall; although the trends in knowledge were similar these did not reach significance. There was evidence of interaction in the case of preferences, the changes occurring mainly in the rural schools. There were no significant changes in the control group (Table 1).

The percentage distribution of healthy and unhealthy choices of individual items varied significantly for some food pairs between the intervention and control schools in each section of the questionnaire at baseline (Table 2). Seven behaviour item choices favoured the intervention group and 12 preference items. Conversely, the control children performed significantly better on nine knowledge items. After intervention nine items altered significantly in the behaviour section, six in the preference section and five in the knowledge section. Among control children two reported behaviour items worsened, as did three preference items, and one knowledge item improved.

Schools were also compared according to whether they were disadvantaged or not. This was confined to intervention schools (689 children) since the sampling procedure resulted in control schools being designated as advantaged only. Disadvantaged schools were overwhelmingly in urban areas (74\%) compared to $26 \%$ in rural areas. Forty-four per cent of advantaged children were located in urban schools with the remaining $56 \%$ in rural areas. A three-way ANOVA between advantage/disadvantage, urban/rural and pre/post groupings revealed that the benefits of the intervention were seen mainly for children in schools in advantaged areas $(f=5.606, P=0.018)$ and this effect remained significant when urban or rural location was taken into account.

\section{Findings from food diaries}

These results are summarized in Table $3 \mathrm{a}$ and $\mathrm{b}$. At baseline the intervention group demonstrated significantly higher percentages than controls in those eating the recommended amounts in two of the four food groups, those eating three or more helpings of dairy products per day, or six or more helpings of cereals per day. Well over one-third of control children consumed dairy products once or less daily. Overall there were very low amounts of fruit and vegetables consumed at baseline; nearly half of the intervention children and two-thirds of the control children consumed these less than once daily. There were also differences between overall urban and rural groups at baseline so that the 
Table 2 Food-pairing questionnaires, percentage of children choosing the healthier option in each pair, pre- and post-intervention in both intervention and control schools

\begin{tabular}{|c|c|c|c|c|c|c|c|c|c|c|c|c|}
\hline \multirow{3}{*}{$\begin{array}{l}\text { Food } \\
\text { pairs }\end{array}$} & \multicolumn{6}{|c|}{ Intervention (pre, $n=353$; post, $n=336$ ) } & \multicolumn{6}{|c|}{ Control (pre, $n=308$; post, $n=274$ ) } \\
\hline & \multicolumn{2}{|c|}{ Behaviour } & \multicolumn{2}{|c|}{ Preference } & \multicolumn{2}{|c|}{ Knowledge } & \multicolumn{2}{|c|}{ Behaviour } & \multicolumn{2}{|c|}{ Preference } & \multicolumn{2}{|c|}{ Knowledge } \\
\hline & Pre & Post & Pre & Post & Pre & Post & Pre & Post & Pre & Post & Pre & Post \\
\hline 1 & $75^{*}$ & $85 t$ & $41^{*}$ & 43 & 96 & 98 & 68 & 73 & 25 & 19 & 97 & 99 \\
\hline 2 & $70^{*}$ & 65 & $38^{*}$ & $50 t$ & 98 & 98 & 51 & 48 & 27 & $19 t$ & 99 & 99 \\
\hline 3 & 27 & $43 t$ & 31 & $51 \dagger$ & 72 & $95+$ & 25 & 21 & 29 & 33 & $85^{\star}$ & 90 \\
\hline 4 & 73 & $84 \dagger$ & $62^{*}$ & 67 & 95 & $99+$ & 73 & 74 & 51 & 46 & $99^{*}$ & 99 \\
\hline 5 & $66^{*}$ & $76+$ & $55^{*}$ & $64 t$ & 96 & 98 & 50 & 46 & 38 & 33 & 99 & 98 \\
\hline 6 & 62 & 62 & 43 & $51 \dagger$ & 81 & $87 \dagger$ & 60 & 63 & 44 & 41 & $92^{*}$ & 92 \\
\hline 7 & $72^{*}$ & $80 t$ & $59^{*}$ & 65 & 97 & 98 & 59 & 55 & 39 & 33 & 98 & 99 \\
\hline 8 & 55 & $64 t$ & $38^{*}$ & $46+$ & 98 & 99 & 51 & 45 & 21 & 18 & 99 & 98 \\
\hline 9 & 36 & $44 \dagger$ & 51 & 53 & 54 & $62 \dagger$ & 35 & 37 & 55 & 58 & 54 & $67 \dagger$ \\
\hline 10 & $71^{*}$ & 77 & $48^{*}$ & 52 & 97 & 98 & 60 & 64 & 26 & 22 & 99 & 99 \\
\hline 11 & $73^{*}$ & 71 & $48^{*}$ & 55 & 97 & 98 & 58 & 55 & 31 & $21 \dagger$ & 98 & 97 \\
\hline 12 & 68 & 73 & $49^{*}$ & 55 & 96 & 97 & 67 & $56+$ & 35 & 33 & $99^{*}$ & 98 \\
\hline 13 & 49 & 56 & 33 & $44 \dagger$ & 85 & 89 & 51 & 47 & 33 & 28 & $94^{*}$ & 96 \\
\hline 14 & 44 & $52+$ & 49 & 56 & 79 & 84 & 46 & 46 & 50 & 45 & $89^{*}$ & 89 \\
\hline 15 & $63^{*}$ & $71 t$ & $59^{*}$ & 64 & 90 & 92 & 52 & 54 & 50 & 51 & 91 & 93 \\
\hline 16 & 41 & 46 & 46 & 46 & 62 & $70 \dagger$ & 38 & 37 & 38 & 37 & $74^{*}$ & 80 \\
\hline 17 & 71 & 72 & $54^{*}$ & 50 & 94 & 96 & 72 & $59+$ & 36 & $26 t$ & $97^{*}$ & 97 \\
\hline 18 & 29 & 35 & $36^{*}$ & 39 & 54 & 60 & 23 & 21 & 29 & 32 & $68^{*}$ & 70 \\
\hline
\end{tabular}

Food pairs: 1, milk/pop; 2, apple/crisps; 3, brown/white bread; 4, yoghurt/iced bun; 5, weetabix/sugared cereal; 6, chicken/burger; 7, juice/pop; 8, apple/ chocolate; 9 , pizza/sausage and chips; 10, water/pop; 11, digestive biscuits/chocolate; 12, orange/cake; 13, baked potato/chips; 14, low fat/full fat milk; 15, cheese/jam; 16, broccoli/carrot; 17, yoghurt/ice-cream; 18, fish/meat.

* Significant at baseline in intervention compared with control children.

† Significant post-intervention compared with pre-intervention.

rural groups tended to have a healthier eating pattern at baseline than their urban counterparts. Although urban children were significantly more likely to consume three or more dairy products daily $(P=0.001)$, rural children ate more meat products daily $(P=0.009)$, more cereals $(P=0.016)$, less salty snacks $(P=0.018)$ and less high sugar drinks $(P=0.001)$.

Following intervention there were no significant changes in the control group but the number of intervention children consuming the recommended amount of fruit and vegetables (four or more per day), improved, albeit small in percentage terms, from a very low base and the consumption of high sugar snacks had fallen. Overall, post-intervention beneficial patterns compared with controls were retained in reported consumption of dairy products and cereals, and improved for fruit and vegetables and salty snacks. There were also some differences within urban and rural groupings in terms of changes. For instance in the case of chipped potatoes nearly half of the rural intervention group had had no chips in the previous week, which was significantly different from their urban counterparts, as was consumption of salty snacks. Numbers in the control rural group were very small, however.

\section{Discussion}

The findings of this evaluation indicate that the NEAPS programme is adaptable to different cultural environments. As in the case of previous studies there was evidence that some knowledge items and overall preferences had altered in the desired direction and, although small, there were also some indications of an impact on behaviours ${ }^{1,11}$. In theory, since this was an open study, the children could have reported what they anticipated they should, so explaining the apparent improvements. However, in itself this would indicate that the programme was successful in one educational objective of teaching children appropriate eating habits. There was also good consistency between the questionnaire and diary, particularly in the fact that both identified differences in eating patterns at baseline between intervention and control children and also in patterns of change, particularly among rural children. The changes seen could in some ways reflect a regression towards the mean effect though there were no significant changes among controls. Indeed the fact that pre- and post-test results using both instruments changed very little in controls suggests the instruments were a good measure of knowledge and behaviour. This was a quasi-experimental study design and the schools were selected for pragmatic reasons which meant that they were not directly comparable. The differences at baseline seen in both questionnaire and diary data can be explained by demographic factors. The fact that these were influential both of baseline dietary patterns and of programme impact is an important finding in itself. Modern health education initiatives stress lifeskills development ${ }^{27}$ and an integrated approach as well as the context and setting of such initiatives, and the WHO's Health Promoting 
Table 3a Food diaries: percentage of children consuming food items at different frequencies pre- and post-intervention. Intervention and control groups are also divided according to whether their school was in an urban or rural area

\begin{tabular}{|c|c|c|c|c|c|c|c|c|c|c|c|c|}
\hline \multirow{3}{*}{$\begin{array}{l}\text { No. of } \\
\text { servings } \\
\text { per day }\end{array}$} & \multicolumn{6}{|c|}{ Intervention } & \multicolumn{6}{|c|}{ Control } \\
\hline & \multicolumn{2}{|c|}{$\begin{array}{c}\text { All } \\
(n=133)\end{array}$} & \multicolumn{2}{|c|}{$\begin{array}{c}\text { Urban } \\
(n=86)\end{array}$} & \multicolumn{2}{|c|}{$\begin{array}{c}\text { Rural } \\
(n=47)\end{array}$} & \multicolumn{2}{|c|}{$\begin{array}{c}\text { All } \\
(n=54)\end{array}$} & \multicolumn{2}{|c|}{$\begin{array}{c}\text { Urban } \\
(n=43)\end{array}$} & \multicolumn{2}{|c|}{$\begin{array}{c}\text { Rural } \\
(n=11)\end{array}$} \\
\hline & Pre & Post & Pre & Post & Pre & Post & Pre & Post & Pre & Post & Pre & Post \\
\hline \multicolumn{13}{|l|}{ Meats } \\
\hline$<1$ & 19 & 27 & 21 & 27 & 17 & 28 & 28 & 33 & 33 & 35 & 9 & 27 \\
\hline 1 & 56 & 54 & 63 & 55 & 45 & 51 & 56 & 56 & 56 & 58 & 54 & 45 \\
\hline 2 & 10 & 10 & 12 & 9 & 8 & 11 & 15 & 9 & 9 & 5 & 36 & 27 \\
\hline$>2$ & 13 & 9 & 5 & 8 & 30 & 11 & 2 & 2 & 2 & 2 & 0 & 0 \\
\hline \multicolumn{13}{|c|}{ Dairy products* } \\
\hline$<1$ & 18 & 16 & 13 & 19 & 28 & 11 & 39 & 35 & 39 & 37 & 26 & 27 \\
\hline 1 & 38 & 36 & 48 & 39 & 19 & 30 & 41 & 37 & 39 & 37 & 45 & 36 \\
\hline 2 & 23 & 30 & 16 & 29 & 34 & 32 & 15 & 18 & 14 & 16 & 18 & 27 \\
\hline 3 & 7 & 5 & 5 & 3 & 11 & 8 & 2 & 2 & 2 & 2 & 0 & 0 \\
\hline$\geqslant 3$ & $15 \dagger$ & 13 & 19 & 9 & 8 & 19 & 4 & 7 & 5 & 7 & 0 & 9 \\
\hline \multicolumn{13}{|l|}{ Cereals* } \\
\hline$<3$ & 0 & 4 & 0 & 2 & 0 & 4 & 6 & 2 & 7 & 2 & 0 & 0 \\
\hline $3-4$ & 15 & 15 & 22 & 20 & 2 & 6 & 26 & 33 & 30 & 37 & 9 & 18 \\
\hline $5-6$ & 21 & 29 & 17 & 32 & 28 & 25 & 31 & 30 & 33 & 33 & 27 & 18 \\
\hline $7-8$ & $50 \dagger$ & 39 & 49 & 36 & 53 & 45 & 31 & 33 & 28 & 26 & 45 & 64 \\
\hline$>8$ & $13 \dagger$ & 13 & 12 & 9 & 17 & 19 & 6 & 2 & 2 & 2 & 18 & 0 \\
\hline \multicolumn{13}{|c|}{ Fruit and vegetables ${ }^{*}$} \\
\hline$<1$ & 47 & 48 & 55 & 56 & 32 & 34 & 65 & 74 & 65 & 72 & 64 & 82 \\
\hline 1 & 35 & 34 & 28 & 29 & 47 & 43 & 26 & 22 & 26 & 23 & 27 & 18 \\
\hline 2 & 13 & 12 & 13 & 9 & 13 & 17 & 9 & 2 & 9 & 2 & 9 & 0 \\
\hline 3 & 5 & 4 & 3 & 2 & 8 & 6 & 0 & 2 & 0 & 2 & 0 & 0 \\
\hline$\geqslant 4$ & 1 & 2 & 1 & 2 & 0 & 0 & 0 & 0 & 0 & 0 & 0 & 0 \\
\hline
\end{tabular}

Note these are rounded averages so not all columns total 100 exactly.

${ }^{*} P<0.01$, post-test, intervention versus control groups.

$\dagger P<0.01$, baseline, intervention versus control groups.

Schools Network is a good example ${ }^{28}$. Efforts to improve dietary behaviour in those who are financially disadvantaged must continue to address the root causes as well as providing supportive education. Our surveys of parents and teachers indicate their support but this clearly needs to be sustained in those at greatest disadvantage and a combined approach with other settings, including primary care, may be appropriate ${ }^{29}$.

The food diaries were not felt by us to be accurate enough to make a full nutritional assessment, but that was not necessary in this context where the educational programme was focused on a balance of food groups using the pyramid concept. In a smaller-scale study a debriefing element could be undertaken with a dietician to clarify exact amounts consumed. This would improve accuracy in this age range but is not feasible for largescale epidemiological assessment.

The NEAPS programme is being introduced more widely into schools, and health promotion will feature strongly in curriculum reform and improved school environments. There are very few long-term outcome measures of such programmes, which are in any case difficult to evaluate, but it would be important to attempt some longitudinal follow-up of this kind. The authors of the CATCH study suggest that if these behavioural changes were sustained into adulthood they would have the potential to reduce cardiovascular risk $^{11}$, and they might also influence patterns of obesity-related diseases including diabetes mellitus and hypertension as well. We conclude that a sustained, appropriate programme of this kind has a place in nutrition health education and could transfer to cultures other than the one in which it was originally developed.

\section{Acknowledgements}

This project was overseen by a joint steering committee comprised of members of the Department of Health and the Health Boards as follows: Mr Owen Metcalfe, Chief Education Officer, Department of Health (Chairperson), Mr Mattie McDonagh, Department of Education, Ms Maura McNally, Health Promotion Officer, North Western Health Board, Ms Ursula O'Dwyer, Consultant Dietician, Department of Health, Ms Mary Jackson and Ms Paula Monks, Health Promotion Unit, Department of Health and Ms Anne McAteer, North Western Health Board. The steering committee would like to thank Dr Cheryl Perry of the Division of Epidemiology at the University of Minnesota who 
Table 3b Food diaries, percentage of children consuming specific food items during the last 5 days pre- and post-intervention. Intervention and control groups are also divided according to whether their school was in an urban or rural area

\begin{tabular}{|c|c|c|c|c|c|c|c|c|c|c|c|c|}
\hline \multirow{3}{*}{$\begin{array}{l}\text { Frequency } \\
\text { in last } \\
5 \text { days }\end{array}$} & \multicolumn{6}{|c|}{ Intervention } & \multicolumn{6}{|c|}{ Control } \\
\hline & \multicolumn{2}{|c|}{$\begin{array}{c}\text { All } \\
(n=133)\end{array}$} & \multicolumn{2}{|c|}{$\begin{array}{l}\text { Urban } \\
(n=86)\end{array}$} & \multicolumn{2}{|c|}{$\begin{array}{c}\text { Rural } \\
(n=47)\end{array}$} & \multicolumn{2}{|c|}{$\begin{array}{c}\text { All } \\
(n=54)\end{array}$} & \multicolumn{2}{|c|}{$\begin{array}{c}\text { Urban } \\
(n=43)\end{array}$} & \multicolumn{2}{|c|}{$\begin{array}{c}\text { Rural } \\
(n=11)\end{array}$} \\
\hline & Pre & Post & Pre & Post & Pre & Post & Pre & Post & Pre & Post & Pre & Post \\
\hline \multicolumn{13}{|l|}{ Chips ${ }^{*}$} \\
\hline Never & 21 & 29 & 14 & 19 & 34 & 47 & 22 & 30 & 23 & 30 & 18 & 27 \\
\hline Once & 27 & 22 & 28 & 25 & 25 & 17 & 30 & 17 & 30 & 14 & 27 & 27 \\
\hline $2-3$ times & 42 & 34 & 48 & 40 & 32 & 23 & 41 & 37 & 37 & 42 & 55 & 18 \\
\hline$\geqslant 4$ times & 10 & 15 & 10 & 16 & 8 & 13 & 7 & 17 & 9 & 14 & 0 & 27 \\
\hline \multicolumn{13}{|l|}{ Orange juice } \\
\hline Never & 52 & 59 & 64 & 71 & 30 & 38 & 28 & 43 & 28 & 39 & 27 & 54 \\
\hline$<3$ times & 19 & 16 & 19 & 14 & 19 & 19 & 30 & 11 & 35 & 14 & 9 & 0 \\
\hline 1/day & 16 & 14 & 10 & 9 & 25 & 23 & 20 & 28 & 16 & 33 & 36 & 9 \\
\hline$>1 /$ day & 13 & 11 & 7 & 6 & 25 & 19 & 22 & 18 & 21 & 14 & 27 & 36 \\
\hline \multicolumn{13}{|l|}{ Salty snack* $\dagger$} \\
\hline Low, < 1/day & 69 & 67 & 63 & 59 & 81 & 83 & 61 & 57 & 56 & 49 & 82 & 91 \\
\hline Moderate, 2-3/day & 16 & 18 & 23 & 25 & 4 & 6 & 13 & 9 & 16 & 12 & 0 & 0 \\
\hline High, $\geqslant 4 /$ day & 14 & 14 & 14 & 16 & 15 & 11 & 26 & 33 & 28 & 39 & 18 & 9 \\
\hline \multicolumn{13}{|l|}{ High sugar snack } \\
\hline Low, $<2 /$ day & 19 & $35 \ddagger$ & 16 & 28 & 25 & 47 & 31 & 28 & 39 & 33 & 0 & 9 \\
\hline Moderate, 3-4/day & 24 & 23 & 24 & 28 & 23 & 15 & 20 & 18 & 23 & 21 & 9 & 9 \\
\hline High, 1/day & 28 & 21 & 27 & 25 & 30 & 15 & 18 & 28 & 12 & 21 & 45 & 54 \\
\hline V. high, $>1 /$ day & 29 & 20 & 33 & 19 & 21 & 6 & 30 & 26 & 26 & 26 & 45 & 27 \\
\hline \multicolumn{13}{|l|}{ High sugar drink } \\
\hline Low, <2/day & 59 & 51 & 51 & 45 & 74 & 64 & 63 & 50 & 65 & 42 & 54 & 82 \\
\hline Moderate, 3-4/day & 14 & 23 & 16 & 28 & 11 & 13 & 13 & 20 & 9 & 23 & 27 & 9 \\
\hline High, 1/day & 24 & 16 & 33 & 19 & 8 & 11 & 18 & 22 & 19 & 26 & 18 & 9 \\
\hline V. high, $>1 /$ day & 2 & 10 & 0 & 8 & 6 & 13 & 6 & 7 & 7 & 9 & 0 & 0 \\
\hline
\end{tabular}

Note these are rounded averages so not all columns total 100 exactly.

${ }^{*} P<0.01$, post-test, urban versus rural area.

$\dagger P<0.05$, post-test, intervention versus control groups.

$\ddagger P<0.05$, post- versus pre-intervention.

afforded them access to the materials and assessment questionnaires. The National Nutrition Surveillance Centre, which is grant funded by the Department of Health, was asked to undertake the project evaluation on which this report is based.

\section{References}

1 Arbeit ML, Serpas DC, Johnson CC, Forcier JE, Berenson GS. The implementation of a cardiovascular school health promotion program: utilisation and impact of a school health advisory committee-the Heart Smart Program. Health Educ. Res. 1991; 6: 423-30.

2 Coates TJ, Jeffrey RW, Slinkard LA. Heart healthy eating and exercise: introducing and maintaining changes in health behaviour. Am. J. Public Health 1981; 71: 15-23.

3 Coates TJ, Barofsky I, Saylor KE, et al. Modifying the snack food consumption patterns of inner city high school students: the great sensations study. Prev. Med. 1985; 14: $234-7$.

4 Howie SM. Nutrition education for children under 12 years in north Staffordshire. Hum. Nutr. Appl. Nutr. 1983; 37a: $54-$ 8.

5 Cade J. Nutrition education in primary schools in Hampshire. J. Hum. Nutr. Diet. 1990; 3: 413-22.

6 Perry CL, Griffen G, Murray DM. Assessing needs for youth health promotion. Prev. Med. 1985; 14: 379-93.
7 Perry CL, Mullis RM, Maile MC. Modifying the eating behaviour of young children. J. Sch. Health 1985; 55: 399-402.

8 Perry CL, Klepp KI, Schultz JM. Primary prevention of cardiovascular disease: community-wide strategies for youth. J. Consult. Clin. Psychol. 1988; 56: 358-64.

9 Shilton T, Corti B. School heart health promotion-National Heart Foundation of Australia's activities. Hygie 1992; 11 $11-16$.

10 Iammarino NK, Laufman L, Scott LW, Weinberg AD. Development and evaluation of the Help your Heart diet game. Hygie 1987; 4: 15-19.

11 Webber LS, Osganion SK, Feldman HA, et al. Cardiovascular risk factors among children after a 2.5 year intervention-the CATCH study. Prev. Med. 1996; 25: 432-41.

12 Pittman KP, Hayman LL. Determinants of risk for cardiovascular disease during school-age/adolescent transition. Prog. Cardiovasc. Nurs. 1997; 12(4): 12-22.

13 Webber LS, Cresanta JL, Voors AW, et al. Tracking of cardiovascular disease risk factors in school-age children. J. Chron. Dis. 1983; 36: 647-60.

14 Berenson GS, Wattingney WA, Bao W, Srinivasan SR, Radhakrishnamurthy B. Rationale to study the early natural history of heart disease: the Bogalusa Heart Study. Am. J. Med. Sci. 1995; 310 (Suppl. 1); S22-8.

15 McGill HC. Nutrition in early life and cardiovascular disease. Curr. Opin. Lipidol. 1998; 9(1): 23-7.

16 Berenson GS, Srinivasan SR, Bao W, Newman WP, Tracy RE, Wattingney WA. Association between multiple cardiovascular risk factors and atherosclerosis in children and young 
adults. The Bogalusa Heart Study. N. Engl. J. Med. 1998; 338(23): 1650-6.

17 Strong WB, Decklegaum RJ, Gidding S, et al. Integrated cardiovascular health promotion in childhood. AHA Medical/ Scientific Statement. Circulation 1992; 85: 1638-50.

18 Gormley TR, Walshe T. Assessment of school meals and of weights/heights of primary school children in inner city Dublin schools. Ir. J. Food Sci. Technol. 1991; 15: 1-15.

19 Adamson AJ, Rugg-Gunn AJ, Appleton DR, Butler TJ, Hackett AF. Dietary sources of energy, protein, unavailable carbohydrate and fat in 11-12 year old English children in 1990 compared with results in 1980. J. Hum. Nutr. Diet. 1992; 5: 371-85.

20 Cunningham K. Young People and Their Food Choices. Dublin: Irish Nutrition and Dietetic Institute, 1993.

21 O'Connor M, Kiely D, Mulvihill M, et al. School Nutrition Survey. Ir. Med.J. 1993; 86: 89-91.

22 McLaughlin B, Gormley TR, Wickham C. Nutritional Quality of Children's School Pack Lunches. Home Food Science Information Technical Bulletin No. 6. An Foras Taluntais, 1982.

23 Hackett AF, Jarvis SN, Matthews JNS. A study of the eating habits of 11 and 12 year old children before and 1 year after the start of a healthy eating campaign in Northumberland. J. Hum. Nutr. Diet. 1990; 3: 323-32.

24 Pollack M. Evaluating school health education. In: Pollock $\mathrm{M}$, ed. Planning and Implementing Health Education in Schools. USA: Mayfield Publishing Co., 1987; 228-60.

25 Hochbaum G. Certain problems in evaluating health education. Health Values 1982; 6: 14-21.

26 Bandura A. Social Learning Theory. New Jersey: Prentice Hall, 1977.

27 Nic Gabhainn S, Kelleher CC. Evaluation of the North Western Health Boards Lifeskills Health Education Programme. Gallway: Centre for Health Promotion Studies, 1995.

28 Nic Gabhainn S, Kelleher CC. and the INHPS Steering Committee. Evaluation of the Irish Health Promoting Schools Network. Dublin, Republic of Ireland: Department of Health, 1998.

29 O’Donnell M, Kelleher CC, Fallon U. Process evaluation of a health education resource material for children: Galway Health Project. Proc. Nutr. Soc. (in press). 